\title{
Maximum Decompressive Hemicraniectomy for Patients with Malignant Hemispheric Infarction
}

\author{
Youngseok Kwak', Byoung-Joon Kim², Jaechan Park ${ }^{2}$ \\ 'Department of Neurosurgery, School of Medicine, Catholic University of Daegu; ' Department of Neurosurgery, \\ School of Medicine, Kyungpook National University, Daegu, Republic of Korea
}

Objective : The authors applied maximum external decompression for malignant hemispheric infarction and investigated the functional outcome according to the patient age.

Methods : Twenty-five patients with malignant hemispheric infarction were treated using a hemicraniectomy with maximum external decompression, comprising a larger $(>14 \mathrm{~cm})$ hemicraniectomy, resection of the temporalis muscle and its fascia, spaciously expansive duraplasty, and approximation of the skin flap. The medical and diagnostic imaging records for the patients were reviewed, and 1-year functional outcome data obtained for the younger group (aged $\leq 60$ years) and elderly group (aged $>60$ years). Results : The patients $(n=25)$ who underwent maximum surgical decompression revealed a minimal mortality rate $(n=2,8.0 \%)$. The patients $(n=14)$ in the younger group all survived with mRS scores of $2 \quad(n=1$, $7.1 \%), 3(n=7,50.0 \%), 4(n=3,21.4 \%)$, or $5(n=3,21.4 \%)$. A majority of the younger patients $(57.1 \%$ with $\mathrm{mRS} \leq 3)$ lived with functional independence. When the 1-year mRS scores were dichotomized between favorable $(m R S \leq 3)$ and unfavorable (mRS $\geq 4$ ) outcomes, the younger group had significantly more patients with a favorable outcome than the elderly group $(57.1 \%$ versus $9.1 \%, p=0.033)$. In contrast, in the elderly group, most patients showed unfavorable outcomes with the mRS scores of $4(n=5,45.5 \%), 5(n=3,27.3 \%)$, or $6(n=2,18.2 \%)$, whereas only one patient showed favorable outcome (mRS 3). A majority of the elderly patients (45.5\% with mRS 4) survived with moderately severe disability.

Conclusion : For malignant hemispheric infarction, a hemicraniectomy with maximum external decompression was found to considerably increase survival with a favorable outcome in functional independence (mRS $\leq 3$ ) for younger patients aged $\leq 60$ years. It can be optimal surgical treatment for younger patients.

Keywords Cerebral infarction, Decompressive hemicraniectomy, Surgical decompression, Temporalis muscle, Treatment outcome

\author{
J Cerebrovasc Endovasc Neurosurg. \\ 2019 September;21(3):138-143 \\ Received : 17 June 2019 \\ Revised : 2 September 2019 \\ Accepted : 18 September 2019 \\ Correspondence to Jaechan Park \\ Department of Neurosurgery Kyungpook \\ National University Hospital 50, Samduk 2-ga, \\ Jung-gu, Daegu, Republic of Korea, 700-721 \\ Tel : +82-53-420-5656 \\ Fax : +82-53-423-0504 \\ E-mail : jparkmd@hotmail.com \\ ORCID : http://orcid.org/0000-0001-7572-3260
}

This is an Open Access article distributed under the terms of the Creative Commons Attribution NonCommercial License /http://creativecommonsorg/licomser/by-nc/3.0) censes/by-nc/3.0) Which permits unrestricted nonmedium, provided the original work is properly cited.

\section{INTRODUCTION}

Despite any medical treatment, malignant hemispheric infarction induced by acute occlusion of either the internal carotid artery (ICA) or proximal middle cerebral artery (MCA) has a high mortality related to massive brain swelling and cerebral herniation. ${ }^{13}$ However, surgical decompression with a hemi- 
craniectomy is an efficient way to reduce the risk of fatal cerebral herniation by allowing the infarcted swollen brain to expand outside the cranium. ${ }^{2-4)(6) 8112) 14 \text { ) }}$ The positive effects of decompressive surgery for malignant hemispheric infarction were approved based on the recent multi-center randomized clinical trials. ${ }^{8) 14)}$

However, the surgical techniques applied in these recent clinical trials, comprising a hemicraniectomy with a diameter $>12 \mathrm{~cm}$, expansive duraplasty, and approximation of the temporalis muscle and skin flap, would seem to be suboptimal for maximizing external herniation of infarcted brain tissue. ${ }^{5778) 15)}$ Accordingly, the authors applied maximum external decompression for malignant hemispheric infarction, comprising a larger $(>14 \mathrm{~cm})$ hemicraniectomy, spaciously expansive duraplasty, resection of the temporalis muscle and its fascia, and approximation of the skin flap. The functional outcome was then investigated and compared with the historical control using a conventional surgical technique.

\section{MATERIALS AND METHODS}

\section{Patient population and data collection}

From January 2011 to December 2014, 25 patients with malignant hemispheric infarction were treated using a decompressive hemicraniectomy with resection of the temporalis muscle at the authors' institution. The inclusion criteria for this study included 1) age $\geq$ 20 years, 2) acute ischemic stroke in the MCA territory, with or without additional infarction in the territory of the ACA or PCA, 3) occlusion of either the ICA or proximal MCA, 4) maximum external decompression with resection of the temporalis muscle and fascia, 5) timely operation without delay, and 5) evaluation of the 1-year functional outcome using mRS. Meanwhile, the exclusion criteria included 1) acute infarction in the whole cerebral hemisphere and 2) bilateral fixed dilated pupils.

The medical and diagnostic imaging records for the patients were reviewed, including the demographics, clinical characteristics, GCS score at admission, NIHSS score at admission, preoperative infarct volume as shown on CT scans, and time interval between ischemic stroke and surgical decompression.

In addition, the 1-year functional outcome data was obtained based on documentation from follow-up visits to the outpatient clinic or a simplified mRS questionnaire conducted over the phone by an independent observer (B.K.). ${ }^{1)}$ A favorable or unfavorable functional outcome was determined based on a dichotomization of the mRS score, 0 (no symptoms at all) to 3 (moderate disability) and 4 (moderately severe) to 6 (death), respectively.

\section{Maximum external decompression}

Timely surgical decompression was performed. The operation was done before or immediately after any neurological deterioration related to brain swelling, including an altered consciousness level, pupil asymmetry, and aggravated hemiparesis. ${ }^{913)}$

The surgical technique used to achieve maximum external decompression was previously reported as a technical note by the current authors. ${ }^{10)}$ The scalp is elevated using a large question-mark incision with a posterior limit of $5 \mathrm{~cm}$ from the external auditory canal. The temporalis muscle and its fascia are then resected at the level of the zygomatic arch. This reduces the temporal lobe compression from the swollen temporal muscle and augments the expansibility of the extradural soft tissue for free external herniation of the swollen brain (Fig. 1).

The hemicraniectomy involves the removal of a large fronto-temporo-parietal bone flap with a posterior limit of $5 \mathrm{~cm}$ from the external auditory canal and superior limit of $2 \mathrm{~cm}$ from the midline. The anteroposterior diameter of the bone flap should be larger than $14 \mathrm{~cm}$.

Following a stellate-shaped dural incision, expansive duraplasty is performed spaciously using an artificial dura substitute. The infarcted brain tissue is not removed except in extremely severe cases, such as severe hemorrhagic transformation or whole hemispheric infarction. Meticulous hemostasis and place- 


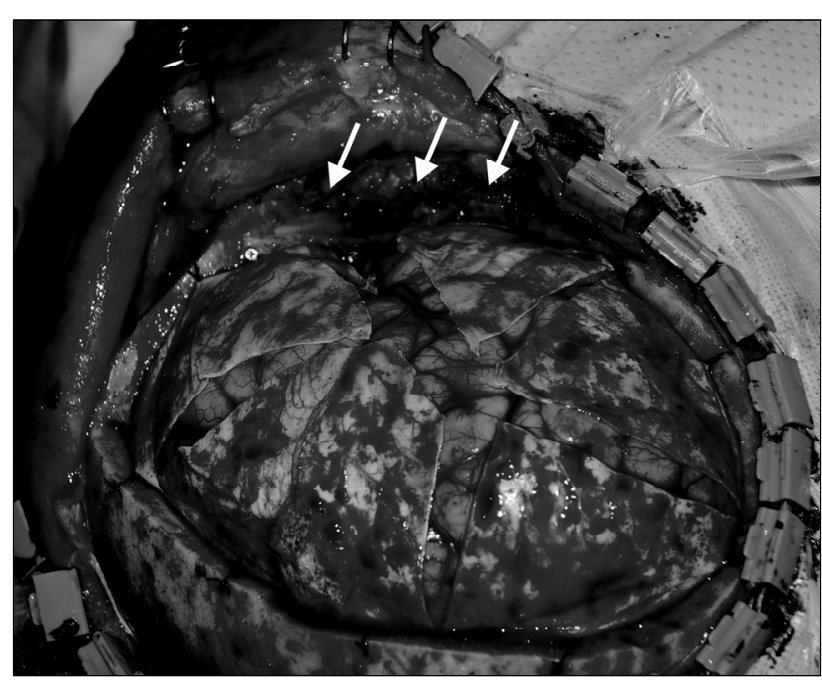

Fig. 1. Intraoperative photograph showing hemicraniectomy with maximum external decompression. The temporalis muscle (arrows) and its fascia are cut at the level of the zygomatic arch.

ment of closed suction drains are performed to prevent a postoperative subgaleal hematoma, and the overlying skin is approximated.

\section{Statistical analysis}

The statistical analyses were performed with the aid of commercially available statistics software (SPSS version 19.0; IBM Corp., New York, United States). The statistical tests used to determine the significance of the differences in the variables are listed in the data tables. The results were considered significant for probability values less than 0.05 .

\section{RESULTS}

\section{Patient characteristics}

A summary of the patient characteristics, including the clinical and radiological characteristics, and 1-year functional outcomes, is shown in Table 1 . The patients were grouped into younger (age $\leq 60$ years) and elderly (age $>60$ years) patients. It enabled us to compare the results with the previous reports in literature.8)14) The mean age of the younger group was 47.6 \pm 8.9 years (range, 31-59 years), while a mean age of the elderly group was 67.0 \pm 3.9 years (range, 61-73 years). The younger and elderly groups were well matched without statistical difference as regards patient gender, the occluded vessel, time interval between stroke onset and the craniectomy, GCS at admission, NIHSS at admission, and preoperative infarct volume on CT scans. The younger patient population consisted of 10 men $(71.4 \%)$ and 4 women $(28.6 \%)$, while the elderly patient population consisted of 4 men $(36.4 \%)$ and 7 women $(63.6 \%)$.

At admission, the GCS scores ranged from 8 to 15 (mean \pm SD: $12.0 \pm 2.7)$ for the younger group and also from 8 to 15 (mean \pm SD: 11.5 \pm 2.8 ) for the elderly group, while the NIHSS scores ranged from 15 to 25 (mean \pm SD: $18.9 \pm 3.0$ ) for the younger group and from 15 to 33 (mean \pm SD: $19.3 \pm 5.5$ ) for the elderly group. Based on the preoperative CT scans, the assessed infarct volume ranged from $170 \mathrm{~mL}$ to $362 \mathrm{~mL}$ (mean $\pm \mathrm{SD}$ : $276.7 \pm 57.6 \mathrm{~mL}$ ) for the younger group and from 185 $\mathrm{mL}$ to $380 \mathrm{~mL}$ (mean $\pm \mathrm{SD}: 273.5 \pm 68.7 \mathrm{~mL}$ ) for the elderly group.

Decompressive surgery was performed before or immediately after neurological deterioration due to brain swelling. For the younger group, the time interval between stroke onset and the craniectomy ranged from $19 \mathrm{hrs}$ to $79 \mathrm{hrs}$ (mean \pm SD : $38.7 \pm 19.8 \mathrm{hrs}$ ), with the operation occurring within $\leq 48$ hours in the case of 10 patients $(71.4 \%)$ and $>48$ hours in the case of 4 patients $(28.6 \%)$. Meanwhile, for the elderly group, the time interval between stroke onset and the craniectomy ranged from $18 \mathrm{hrs}$ to $73 \mathrm{hrs}$ (mean \pm SD : $34.8 \pm 18.8 \mathrm{hrs})$, with the operation occurring within $\leq$ 48 hours in the case of 8 patients $(72.7 \%)$ and $>48$ hours in the case of 3 patients $(27.3 \%)$.

\section{1-year functional outcomes}

The patients $(n=25)$ who underwent maximum surgical decompression revealed a minimal mortality rate $(n=2,8.0 \%)$. The reduced mortality resulted in survival with or without functional independence.

The patients $(n=14)$ in the younger group all survived with mRS scores of $2(n=1,7.1 \%), 3 \quad(n=7$, $50.0 \%), 4(n=3,21.4 \%)$, or $5(n=3,21.4 \%)$. A majority of the younger patients $(57.1 \%$ with $\mathrm{mRS} \leq 3)$ lived 
Table 1. Characteristics and 1-year functional outcomes for infarcted patients after hemicraniectomy with maximum external decompression

\begin{tabular}{|c|c|c|c|}
\hline \multirow[b]{2}{*}{ Patient Characteristics } & \multicolumn{2}{|c|}{ No. (\%) of Patients } & \multirow[b]{2}{*}{ p Value* } \\
\hline & $\begin{array}{c}\text { Aged } \leq 60 \text { years } \\
(n=14)\end{array}$ & $\begin{array}{c}\text { Aged }>60 \text { years } \\
\qquad(n=11)\end{array}$ & \\
\hline Gender & & & $0.116^{\ddagger}$ \\
\hline Male & $10(71.4)$ & $4(36.4)$ & \\
\hline Female & 4 (28.6) & $7(63.6)$ & \\
\hline Infarcted hemisphere & & & $0.042^{\ddagger}$ \\
\hline Dominant side & $7(50.0)$ & $4(36.4)$ & \\
\hline Non-dominant side & $7(50.0)$ & $7(63.6)$ & \\
\hline Occluded vessel & & & $0.350^{\ddagger}$ \\
\hline ICA & $2(14.3)$ & $4(36.4)$ & \\
\hline Proximal MCA & 12 (85.7) & 7 (63.6) & \\
\hline Time interval between stroke onset and craniectomy & & & $0.622^{\dagger}$ \\
\hline $\begin{array}{l}\text { Mean } \pm \text { SD (hrs) } \\
\text { Range (hrs) }\end{array}$ & $\begin{array}{l}38.7 \pm 19.8 \\
19-79\end{array}$ & $\begin{array}{l}34.8 \pm 18.8 \\
18-73\end{array}$ & \\
\hline GCS at admission & & & $0.688^{\dagger}$ \\
\hline Mean \pm SD & $12.0 \pm 2.7$ & $11.5 \pm 2.8$ & \\
\hline Range & $8-15$ & $8-15$ & \\
\hline NIHSS at admission & & & $0.811^{\dagger}$ \\
\hline Mean \pm SD & $18.9 \pm 3.0$ & $19.3 \pm 5.5$ & \\
\hline Range & $15-25$ & $16-33$ & \\
\hline Preoperative infarct volume on CT scans & & & $0.914^{\dagger}$ \\
\hline Mean \pm SD $(\mathrm{mL})$ & $276.7 \pm 57.6$ & $273.5 \pm 68.7$ & \\
\hline Range (mL) & 170-362 & 185-380 & \\
\hline $\begin{array}{l}1-y e a r \text { mRS } \\
0-3\end{array}$ & $8(57.1)$ & $1(9.1)$ & $0.033^{+}$ \\
\hline $4-6$ & $6(42.9)$ & $10(90.9)$ & \\
\hline $\begin{array}{l}\text { CT : computed tomography, DW : diffusion-weighte } \\
\text { Institutes of Health Stroke Scale, SD : standard deviati } \\
\text { * Boldface p values indicate significance. } \\
+ \text { t-test. } \\
\text { f Chi-square test. } \\
\text { \$ Fisher's exact test. }\end{array}$ & ES : Glasgow Coma & mRS : modified Ra & NIHSS : \\
\hline
\end{tabular}

Table 2. Comparison between the present study and representative recent clinical trials*

\begin{tabular}{|c|c|c|c|c|c|c|}
\hline \multirow[b]{2}{*}{ mRS } & \multicolumn{2}{|c|}{ Pooled analysis ${ }^{14)}$ (Age $\leq 60 \mathrm{y}$ ) } & \multicolumn{2}{|c|}{ Current Data } & \multicolumn{2}{|c|}{ DESTINY $\|$ Trial $^{8 \mid}$ (Age $>60 \mathrm{y}$ ) } \\
\hline & $\begin{array}{l}\text { Conservative Treatment } \\
\qquad(\mathrm{n}=42)\end{array}$ & $\begin{array}{l}\text { Surgery } \\
(\mathrm{n}=51)\end{array}$ & $\begin{array}{c}\text { Surgery Age } \leq 60 \text { y } \\
(\mathrm{n}=14)\end{array}$ & $\begin{array}{c}\text { Surgery Age }>60 \text { y } \\
(\mathrm{n}=11)\end{array}$ & $\begin{array}{l}\text { Surgery } \\
(\mathrm{n}=47)\end{array}$ & $\begin{array}{l}\text { Conservative Treatment } \\
\qquad(\mathrm{n}=62)\end{array}$ \\
\hline $0-2$ & 1 (2) & 7 (14) & 1 (7) & $0(0)$ & $0(0)$ & $0(0)$ \\
\hline 3 & 8 (19) & 15 (29) & 7 (50) & 1 (9) & $3(6)$ & 3 (5) \\
\hline 4 & $1(2)$ & 16 (31) & $3(21)$ & $5(46)$ & $15(32)$ & 7 (11) \\
\hline 5 & 2 (5) & $2(4)$ & $3(21)$ & 3 (27) & 9 (19) & $5(8)$ \\
\hline 6 & 30 (71) & $11(22)$ & $0(0)$ & $2(18)$ & 20 (43) & 47 (76) \\
\hline
\end{tabular}

$\mathrm{mRS}=$ modified Rankin Scale.

$*$ Values in parentheses are percentage of patients.

with functional independence. When the 1-year mRS scores were dichotomized between favorable (mRS $\leq$ 3) and unfavorable (mRS $\geq 4$ ) outcomes, the younger group had significantly more patients with a favorable outcome than the elderly group $(57.1 \%$ versus 9.1\%, $\mathrm{p}=0.033$ ).

In contrast, in the elderly group, most patients showed unfavorable outcomes with the mRS scores of $4(\mathrm{n}=5,45.5 \%), 5(\mathrm{n}=3,27.3 \%)$, or $6(\mathrm{n}=2,18.2 \%)$, whereas only one patient showed favorable outcome (mRS 3). A majority of the elderly patients $(45.5 \%$ with mRS 4) survived with moderately severe disability.

\section{DISCUSSION}

The surgical outcome of a hemicraniectomy for malignant infarction was improved when using techniques to obtain maximum external decompression in comparison with the clinical trials using a conventional surgical technique. In addition, this positive effect on the functional outcome was particularly significant for younger patents aged $\leq 60$ years (Table 2 ). 
A pooled analysis of three European randomized controlled trials by Vahedi et al.14) for infarcted patients aged $\leq 60$ years revealed that a hemicraniectomy reduced mortality (71\% versus $22 \%$ ) and increased the number of patients with a favorable outcome $(21 \%$ versus $43 \%$ ) when compared with conservative treatment. In the current study, maximum external decompression for patients aged $\leq 60$ years showed $0 \%$ mortality and a further increased number of patients with a favorable outcome (57\%) when compared with the pooled analysis.

For elderly patients aged $>60$ years, a randomized controlled trial (DESTINY II) by Jüttler et al. revealed that a hemicraniectomy reduced mortality when compared with conservative treatment (76\% versus $43 \%$ ), yet did not increase the number of patients with a favorable outcome when compared with conservative treatment.8) The surgery increased the number of patients with moderately severe disability (mRS 4; 11\% versus $32 \%$ ). In the current study, maximum external decompression further decreased the mortality (18\%), while further increasing the number of patients with mRS scores of $4(46 \%)$ when compared with the DESTINY II trial. Notwithstanding, there was no increase in the number of patients with a favorable outcome ( $\mathrm{mRS} \leq 3)$.

When compared with a conventional decompressive hemicraniectomy, the maximum external decompression used in the present study was achieved based on the following technical points: 1) larger hemicraniectomy $>14 \mathrm{~cm}, 2$ ) resection of the temporalis muscle to avoid its compression of the temporal lobe, 3) resection of the inelastic temporalis fascia to increase the expansibility of the extradural soft tissue, 4) spacious expansive duraplasty to accommodate further aggravation of brain swelling, and 5) meticulous hemostasis to avoid a postoperative subgaleal hematoma that would reduce the decompressive effect of the surgery.

The concept of timely surgery used in this study is based on the results of the observational study by
Qureshi et al. ${ }^{11)}$ on the timing of neurological deterioration after massive MCA infarction. In their study, one third of the patients suffered neurological deterioration within 24 hours, another third deteriorated 24-48 hours after stroke onset, and the remaining patients showed later deterioration on day 3-6. The brain swelling and herniation after hemispheric infarction are affected by delayed spontaneous recanalization of the occluded vessel, hemorrhagic transformation of the infarcted brain tissue, and the fluid volume state of the patient. Thus, the appropriate timing for surgery is not simply 24 or 48 hours after stroke onset. Surgical decompression should be performed at the time point before any neurological deterioration related to brain swelling or immediately after the deterioration in a reversible state.

The cosmetic problems caused by resection of the temporalis muscle were minimized using a MEDPOR implant (MEDPOR FLEXBLOCK TF2; Porex Surgical, Inc.) during cranioplasty. ${ }^{10)}$ There were no wound problems or surgical site infections in all our cases.

The current study has several important limitations. First, it was based on a retrospective review of a small case series from a single institution. Second, the surgical results were compared with a historical control. However, the results of our study shed light on the positive effects of the maximum external decompression technique for younger patients. A larger, prospective randomized study is warranted.

\section{CONCLUSIONS}

For malignant hemispheric infarction, a hemicraniectomy with maximum external decompression was found to considerably increase survival with a favorable outcome in functional independence (mRS $\leq$ 3) for younger patients aged $\leq 60$ years. It can be optimal surgical treatment for younger patients.

\section{Disclosure}

The authors report no conflict of interest concerning the materials or methods used in this study or the 
findings specified in this paper.

\section{REFERENCES}

1. Bruno A, Akinwuntan AE, Lin C, Close B, Davis K, Baute $\mathrm{V}$, et al. Simplified modified rankin scale questionnaire: reproducibility over the telephone and validation with quality of life. Stroke. 2011 Aug;42(8):2276-9.

2. Daou B, Kent AP, Montano M, Chalouhi N, Starke RM, Tjoumakaris S, et al. Decompressive hemicraniectomy: predictors of functional outcome in patients with ischemic stroke. Journal of neurosurgery. 2016 Jun;124(6): 1773-9.

3. Geurts M, van der Worp HB, Kappelle LJ, Amelink GJ, Algra A, Hofmeijer J. Surgical decompression for space-occupying cerebral infarction: outcomes at 3 years in the randomized HAMLET trial. Stroke. 2013 Sep;44(9): 2506-8.

4. Gupta R, Connolly ES, Mayer S, Elkind MS. Hemicraniectomy for massive middle cerebral artery territory infarction: a systematic review. Stroke. $2004 \mathrm{Feb} ; 35(2)$ : 539-43.

5. Hofmeijer J, Kappelle LJ, Algra A, Amelink GJ, van Gijn J, van der Worp HB. Surgical decompression for space-occupying cerebral infarction (the Hemicraniectomy After Middle Cerebral Artery infarction with Life-threatening Edema Trial [HAMLET]): a multicentre, open, randomised trial. The Lancet Neurology. 2009 Apr;8(4) :326-33.

6. Huh JS, Shin HS, Shin JJ, Kim TH, Hwang YS, Park SK. Surgical management of massive cerebral infarction. Journal of Korean Neurosurgical Society. 2007 Oct;42(4): 331-6.

7. Juttler E, Schwab S, Schmiedek P, Unterberg A, Hennerici M, Woitzik J, et al. Decompressive Surgery for the Treatment of Malignant Infarction of the Middle
Cerebral Artery (DESTINY): a randomized, controlled trial. Stroke. 2007 Sep;38(9):2518-25.

8. Juttler E, Unterberg A, Woitzik J, Bosel J, Amiri H, Sakowitz OW, et al. Hemicraniectomy in older patients with extensive middle-cerebral-artery stroke. The New England journal of medicine. 2014 Mar 20;370(12): 1091-100.

9. Park J, Goh DH, Sung JK, Hwang YH, Kang DH, Kim Y. Timely assessment of infarct volume and brain atrophy in acute hemispheric infarction for early surgical decompression: strict cutoff criteria with high specificity. Acta neurochirurgica. 2012 Jan;154(1):79-85.

10. Park J, Kim E, Kim GJ, Hur YK, Guthikonda M. External decompressive craniectomy including resection of temporal muscle and fascia in malignant hemispheric infarction. Journal of neurosurgery. 2009 Jan;110(1):101-5.

11. Qureshi AI, Suarez JI, Yahia AM, Mohammad Y, Uzun G, Suri MF, et al. Timing of neurologic deterioration in massive middle cerebral artery infarction: a multicenter review. Critical care medicine. 2003 Jan;31(1):272-7.

12. Robertson SC, Lennarson P, Hasan DM, Traynelis VC. Clinical course and surgical management of massive cerebral infarction. Neurosurgery. 2004 Jul;55(1):55-61; discussion -2 .

13. Ropper AH, Shafran B. Brain edema after stroke. Clinical syndrome and intracranial pressure. Archives of neurology. 1984 Jan;41(1):26-9.

14. Vahedi K, Hofmeijer J, Juettler E, Vicaut E, George B, Algra A, et al. Early decompressive surgery in malignant infarction of the middle cerebral artery: a pooled analysis of three randomised controlled trials. The Lancet Neurology. 2007 Mar;6(3):215-22.

15. Vahedi K, Vicaut E, Mateo J, Kurtz A, Orabi M, Guichard JP, et al. Sequential-design, multicenter, randomized, controlled trial of early decompressive craniectomy in malignant middle cerebral artery infarction (DECIMAL Trial). Stroke. 2007 Sep;38(9):2506-17. 